\title{
Research on the Innovative Training Mode of Compound Talents based on the Training of "Craftsman Spirit"
}

\author{
Tian $\operatorname{Lan}^{1}$ \\ ${ }^{1}$ ChangChun University of Technology, Changchun City, Jilin Province, China, 130012
}

Keywords: Craftsman Spirit; Compound Talents; Innovation; Cultivation Mode

\begin{abstract}
College students can be taken as the main force of social development, and they get the hope of motherland's future. Colleges and universities have the responsibility to cultivate students as complex innovative talents of social development needs. In order to achieve this goal, it is necessary to strengthen 'craftsman spirit' cultivation of college students, guide their study and improve their comprehensive quality. We start from the problems existing in the cultivation of college students' craftsman spirit, expound the existing problems, and analyze the causes. Based on the results of analysis, we put forward an innovative cultivation mode of compound talents under the background of 'craftsman spirit' cultivation, which is helpful to cultivate more high-quality talents and further promote the development of local economy.
\end{abstract}

\section{Introduction}

According to the government's latest work report, the "Craftsman Spirit" [1] was mentioned on different occasions, which is enough to see the government's determination to develop China's advanced manufacturing industry. Many experts have also mentioned ${ }^{[2]}$ that ancient China once created four inventions, but in modern times, China and the world's advanced countries are in a backward state in science and technology competition, in part because young college students lack the spirit of innovation. ${ }^{[3]}$, but they are opportunistic. With Apple's breakthrough in the market value of trillions, more people care about when China can cultivate such a company and realize the transformation from "Made in China" to "Created in China" ${ }^{[4]}$. In this context, many companies care about the quality of their employees, that is, whether employees have strong psychological qualities in addition to their professional knowledge, whether they are serious and responsible for their work, and whether they have Craftsman Spirit. Colleges and universities have the obligation to cultivate compound innovative talents ${ }^{[5]}$, and it is necessary to reform existing teaching objectives instead of simply pursuing graduation rates and enrollment rates. It is necessary to further cultivate college students with Craftsman Spirit and explore feasible talent training models, which will help to cultivate more high-quality talents and further promote the development of local economy.

Craftsman Spirit ${ }^{[6]}$ is a process of craftsmanship and excellence in the production process. In this process, people show a rigorous, meticulous, focused and responsible work attitude ${ }^{[7]}$, as well as a sense of professional identity, responsibility, honor and mission. At home and abroad, many countries have raised Craftsman Spirit to the level of national development ${ }^{[8]}$, and introduced it into the talent cultivation plan to further enhance the overall quality of talents. On March 5, 2016, Premier Li Keqiang [9] proposed "Craftsman Spirit" in the "Government Work Report", and then the word "Craftsman Spirit" quickly became popular., At present, colleges and universities have paid more attention to the cultivation of "Craftsman Spirit", especially in higher vocational colleges

${ }^{10]}$, but there are few studies on undergraduate colleges.

\section{An Overview of the Current Situation of Contemporary College Students' Craftsman Spirit Cultivation}

Colleges and universities should consciously help college students to establish the good character of Craftsman Spirit, and guide them to show their noble spirit of seeking knowledge and strengthen their practical ability. In the process of learning and practice, it is necessary to cultivate students' 
ability to discover problems and solve problems on their own, so that they can cultivate their own attitudes towards things in the process, and thus help them to work in the future. Colleges and universities should regard the cultivation of Craftsman Spirit as a daily business. However, the current educational methods can hardly help college students to cultivate Craftsman Spirit. We need to analyze the existing talent training methods and organize the existing shortcomings.

\section{The Basic Status of the Cultivating College Students' Craftsman Spirit}

According to the questionnaire survey, nearly $85 \%$ of college students have insufficient understanding of Craftsman Spirit. At the same time, nearly $90 \%$ of students believe that Craftsman Spirit is an important quality for future work. At present, many colleges and universities have irregularities in the setting of courses, and it is difficult for students to have full access to Craftsman Spirit. The school lacks due attention to the cultivation of students' overall quality, and lacks correct guidance on students' outlook on life and values, which leads some college students to form a wrong outlook on life and career choice. At work, they have no enterprising mentality, but have chosen to pass. All of these indicate that colleges and universities need to do more work in the teaching and training of Craftsman Spirit to strengthen the understanding of college students' correct concepts, especially to strengthen college students' understanding and learning of Craftsman Spirit.

\section{Problems in the Cultivation of College Students' Craftsman Spirit}

Some colleges and universities lack sufficient attention to the cultivation of College Students' Craftsman Spirit. Therefore, they did not set up courses related to Craftsman Spirit, such as professional ethics, work guides and so on. In the course of ideological and political education, although there is a description about Craftsman Spirit, the explanation is not deep enough. Many teachers mentioned that Craftsman Spirit was just a passing with lack of case analysis and in-depth discussion. According to related surveys, more than $65 \%$ of students said they had no impression about the curriculum of Craftsman Spirit.

When asked if they would give a lecture on Craftsman Spirit, less than 5\% of the students said that the school had a lecture on Craftsman Spirit. We conducted interviews with some students on the development of ideological and political courses. They said that in the classroom, they are all about the direction of life. They didn't explicitly mention Craftsman Spirit, but only mentioned that the work needs to be taken seriously. Some students also said that in the school library, there are few books on Craftsman Spirit, and most college students pay little attention to Craftsman Spirit and do not take the initiative to consult related books.

\section{Analysis of the Reasons for the Lack of Craftsman Spirit among Contemporary College Students}

The cultivation of Craftsman Spirit is a systematic project. College students have a poor understanding of craftsman precision and a lack of understanding of Craftsman Spirit. This is a question that the education community needs to think about, how to strengthen the ideological education of college students, let them better understand Craftsman Spirit, and apply Craftsman Spirit to future work. Therefore, we need to analyze the problems existing in the current College Craftsman Spirit education.

\section{Insufficient School Education}

There is a lack of information on Craftsman Spirit in colleges and universities, no related courses, and a lack of teachers with Craftsman Spirit. Craftsman Spirit helps students to take a better position in a competitive social environment and enable them to grow better. Many colleges and universities also recognize that job literacy is an important issue, and have conducted corresponding lectures and arranged some temporary courses. However, these methods have not attracted the attention of students. Because of the lack of restraint and the inability of students to see the effect, most students regard such courses as irrelevant courses. Most colleges and universities regard exams as the only criterion for testing students, and do not assess their overall quality. Therefore, quality education such as Craftsman Spirit can only become a "work staying on the surface".

The overall quality of teachers needs to be improved. Many teachers use lectures or book-based 
lectures. Students can only passively inculcate, and it is difficult to combine them with reality. The reason is because many teachers, who lack the experience of Craftsman Spirit, do not establish the standards of Craftsman Spirit in their work, and it is difficult to demonstrate. Teachers need to use their own experiences as a practical case, combined with books, to better help students understand the importance of Craftsman Spirit.

\section{Insufficiency among College Students}

Some college students apply for a major that does not match the actual major. This has made it difficult for many students to adapt to the psychological gap and lack motivation. College students need to adapt to the new environment, and their majors do not match, which will further aggravate their mentality of learning. Therefore, in the face of such an environment, they are difficult to show a positive learning attitude and easily relax their own requirements. When they studied Craftsman Spirit, because of their lack of thinking, the teacher's teaching is difficult to play a role for students.

Some college students still have a high level of understanding of the university. They think that in college, as long as the exam is well-tested, they can graduate. This wrong idea leads to many college students with high theoretical level and poor practical ability. In the process of learning Craftsman Spirit, most students simply remembered the theory, passed the exam, did not really understand Craftsman Spirit, and did not develop a good working attitude in the workplace.

\section{There is a Lack of Good Social Environment}

The cultivation of Craftsman Spirit requires a good social environment, which affects people's way of thinking and their attitudes toward work, life, and learning. As a spiritual aspect, Craftsman Spirit needs the promotion of society to attract enough attention of college students, but the current social environment has many obstacles to the cultivation of Craftsman Spirit.

The country lacks rewards for Craftsman Spirit and mistakenly believes that Craftsman Spirit is dirty and tired. Therefore, many college students will not regard Craftsman Spirit as a kind of glory. Instead, they think that Craftsman Spirit is a characteristic of low-level talents. The society needs to strengthen the supervision of Craftsman Spirit. Along with the improvement of living standards, many things are solved through the network. The tools of traversal let people forget the Craftsman Spirit and reduce the constraints of excellent quality. In this case, Craftsman Spirit is no longer important to many college students.

\section{The Cultivation Model of Compound Talents Based on the Cultivation of "Craftsman Spirit"}

Craftsman Spirit is an important quality. It can promote people to work more, get better work results, and also drive the economic development of the entire country. In the cultivation of Craftsman Spirit, colleges and universities need to improve the existing curriculum system, and the society needs to strengthen public opinion guidance. At the same time, it is necessary to change the misunderstanding of college students on Craftsman Spirit. Based on this, we propose a hybrid talent innovation training model based on the background of "Craftsman Spirit".

Constructing a Curriculum System Based on "Craftsman Spirit" to Realize Theoretical

\section{Teaching Innovation}

It is necessary to strengthen the basic curriculum and emphasize the cross-infiltration of the disciplines of science, science and engineering. For example, students in the main repair engineering department must study courses in the humanities, arts and social sciences; students are required to study inter-disciplinary knowledge and to develop students' comprehensive qualities by strengthening cross-infiltration between relevant disciplines.

\section{Design Interdisciplinary Project based on "Craftsman Spirit", and Innovative Classroom Teaching Mode}

The cultivation of compound talents should not be limited to a traditional subject classification. Interdisciplinary learning should be carried out according to the needs of the majors studied, and the concept of Maker education should be introduced to increase the flexibility of the teaching plan. Adhere to multi-professional infiltration in teaching, give full play to the main role of students, strengthen cases and guided teaching, cultivate students' interest in learning, and master relevant knowledge points to cultivate students' innovative ability and comprehensive quality. 


\section{Strengthening Practical Teaching Links based on "Craftsman Spirit" and Attaching Importance to Scientific Research Training}

Through research, the research team believes that colleges and universities should consider the cultivation of talents from various angles, combine production, education and research, and at the same time pay attention to the cooperation between schools and enterprises, and provide a good practice base for talent training. To create conditions for students to accept the enterprise's standardized management concepts and technical knowledge during the school's school management. In practice, focusing on cultivating students' ability to solve practical problems, it is even more necessary to cultivate students' rigorous "Craftsman Spirit" in practice.

\section{Establish a Comprehensive Dynamic Assessment System for Students' Learning}

Change the course to judge the student's academic performance with the final exam, strengthen the assessment and evaluation of the student's learning process, and combine case analysis with basic knowledge assessment. Students are assessed from a variety of aspects, such as the usual work, the expressiveness in the classroom, and the ability to solve and analyze problems. The evaluation focus is changed to the evaluation of students' learning attitude, ideological quality, behavioral habits assessment and cognitive practice of professional knowledge, forming an educational orientation and promoting the cultivation of compound talents.

Focus on Campus Culture based on "Craftsman Spirit" and Cultivate Students' Self-reliance

Paying attention to the campus culture, paying attention to the positive role played by the student associations in arranging learning and activities, giving students greater rights and freedoms, and cultivating students' autonomy, enterprising and hands-on ability. Encourage students to participate in extracurricular activities, to receive more exercise in nature and society, and to improve the overall quality of students.

\section{Conclusion}

As the masters of national construction, college students' ideological consciousness and personal value trend not only determine their personal destiny, but also determine the future of the country. In the current environment, college students do not form good values. Colleges lack the curriculum system of Craftsman Spirit, and the society lacks correct public opinion guidance. As a result, many college students have misunderstandings and even mistakes in the understanding of Craftsman Spirit. This paper introduces Craftsman Spirit with the theme of compound innovative talents training, analyzes the current situation of College students' understanding of Craftsman Spirit, analyzes the reasons for the lack of understanding of Craftsman Spirit, and proposes a model of compound talent innovation training based on the cultivation of Craftsman Spirit. .

In the implementation part, questionnaire survey and interviews are used to conduct investigation and analysis. The subdivision process includes: designing a questionnaire survey, distributing the questionnaires in the form of a network, collecting valid questionnaires, analyzing the data of these questionnaires, classifying the questionnaire data by SPSS software, and applying the obtained results to the teaching practice.

\section{Acknowledgements}

Fund Project: General Course of Higher Education Research in 2017 in Jilin Province High Teaching Association

Fund number: JGJX2017D56

\section{References}

[1] Xiao Qunzhong, \& Liu Yongchun. (2015). Craftsman Spirit and its Contemporary Values. Hunan Social Sciences (6), 6-10.

[2] Hu Huakai. (2014). Thoughts on why Chinese people rarely making major scientific and technological inventions since modern times. Dialectics of Nature Dialogue (4), 121-121. 
[3] Zhou Qian. (2011). On the Education of Innovation Consciousness among Contemporary College Students. People's Forum (24), 152-153.

[4] Shi Zhanzhong. (2013). Rejuvenation and Rise of Great Powers: From "Made in China" to "Made in China". Inheritance (1), 92-93.

[5] Xue Eryong. (2012). Collaborative Innovation and Analysis of Innovative Talents Training Policies in Colleges and Universities. China Higher Education Research (12), 26-31.

[6] Hu Bing, \& Li Xiaolu. (2016). On the New Mission of Ideological and Political Education in Higher Vocational Colleges__Rethinking the Cultivation of "Craftsman Spirit" under the Lack of Reason. Vocational Education Forum (22), 85-89.

[7] Chen Changhui, \& Liu Wei. (2015). Craftsman Spirit--Made in China is Calling, Vocational Education should be Taken. Occupation (20), 14-15.

[8] Yu Zhiming. (2018). Innovation-Driven, Training "Artisan-type" Talents for the Construction of National Central Cities. Henan Education ( Vocational education edition) (2).

[9] Chi Yuzhou. (2017). What is the real "Craftsman Spirit"? Life and Companion (The second half of the month) (5), 11-11.

[10] Wang Liyuan. (2014). The Necessity and Feasibility of Cultivating Students' Craftsman Spirit in Higher Vocational Education. Vocational Education Forum (22), 66-69. 